\title{
Update on new approaches in the management of hepatocellular carcinoma
}

This article was published in the following Dove Press journal:

Hepatic Medicine: Evidence and Research

25 November 2010

Number of times this article has been viewed

\section{Giuseppe Cabibbo',2 \\ Michela Antonucci ${ }^{3}$ \\ Chiara Genco'}

'Sezione di Gastroenterologia, Di.Bi.Mi.S., University of Palermo, Italy; 'Dipartimento di Biopatologia e Metodologie Biomediche, University of Palermo, Italy; ${ }^{3}$ Department of Oncology, Division of General and Oncological Surgery, University of Palermo, Italy
Correspondence: Giuseppe Cabibbo Sezione di Gastroenterologia, Di.Bi.M.I.S., Piazza delle Cliniche 2 , 90127 Palermo, Italy Tel +390916552280 Fax +390916552156 Email g.cab@libero.it

\begin{abstract}
Hepatocellular carcinoma (HCC) is a major health problem. It is currently the third cause of cancer-related death, it is highly prevalent in the Asia-Pacific region and Africa, and is increasing in Western countries. The natural history of HCC is very heterogeneous and prediction of survival in individual patients is not satisfactory because of the wide spectrum of the disease. During the past decade, major advances have been achieved in prevention, through better surveillance of patients at risk, and in therapy through better surgical and ablative therapies and multimodal treatment approaches. Moreover, the increasing knowledge of molecular hepatocarcinogenesis provides the opportunity for targeted therapies. In this setting, the impact of sorafenib on advanced-stage HCC is a landmark finding in the treatment of liver cancer. The role of sorafenib administration as adjuvant therapy after curative treatment is being evaluated in clinical studies. Future research should lead to a molecular classification of the disease and a more personalized treatment approach.
\end{abstract}

Keywords: hepatocellular carcinoma, sorafenib

\section{Introduction to treatment management of hepatocellular carcinoma - update on use of biologics and emerging treatment options}

Hepatocellular carcinoma (HCC) is a major health problem. It is the sixth most common cancer worldwide and the third cause of cancer-related death. ${ }^{1}$ In 2002 at least 600,000 new cases were registered and its incidence and prevalence in US and Western Europe have been increasing during the past decade. In $80 \%$ of cases HCC affects cirrhotic livers and it is now considered the first complication to occur and the major cause of liver-related death. ${ }^{2}$ Principal risk factors for developing cirrhosis and then HCC are chronic liver diseases and in particular chronic $\mathrm{B}$ and $\mathrm{C}$ hepatitis/cirrhosis, alcoholic liver disease and nonalcoholic steatohepatitis-related cirrhosis. ${ }^{3-5}$ Guidelines for HCC management recommend mortality risk estimates as a decision-making support. ${ }^{3}$ Unfortunately, the ability of all the available prognostic scores to predict mortality is far from perfect and none of these systems provide sufficient confidence for the prediction of the outcome in the individual patient with HCC., ${ }^{3,6-8}$

In the absence of an optimum prognostic model, treatment algorithms for patients with HCC in Europe and North America have been prepared on the basis of the Barcelona Clinic Liver Cancer (BCLC) classification., ${ }^{3,9,10}$

The BCLC staging classification for HCC classifies patients as having stages of disease from 0 to D (Figure 1). 


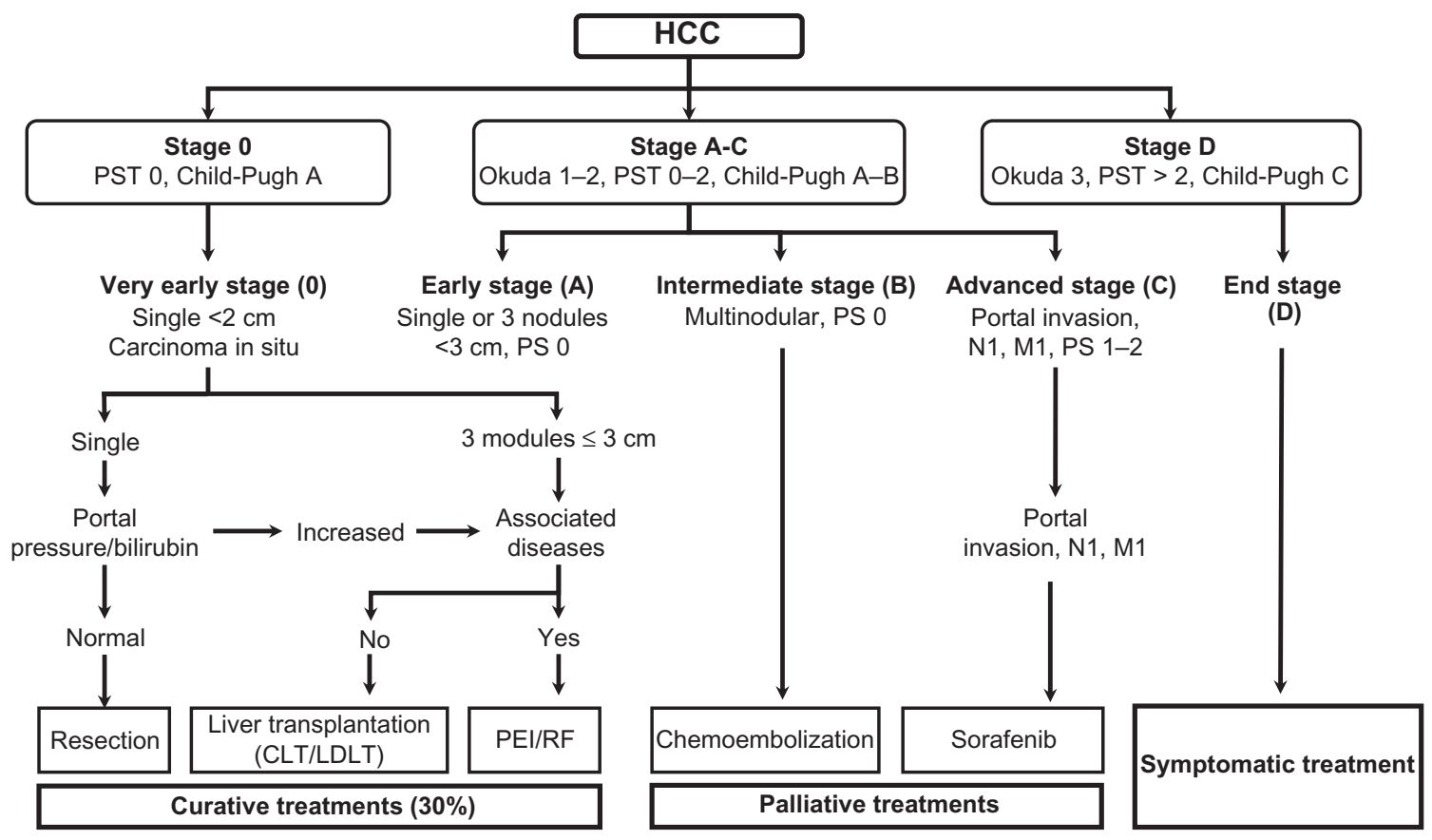

Figure I The Barcelona Clinic Liver Cancer staging system and treatment allocation. Copyright @ 20I0, American Association for the study of Liver Diseases. Adapted with permission from Bruix J, Sherman M. Management of hepatocellular carcinoma: an update. Hepatology. 20I0; I-35. Available from: http://www.aasld.org/practiceguidelines/ Documents/Bookmarked\%20practice\%20Guidelines/Hccupdate20I0.pdf. Accessed on Nov 3, 2010.

Abbreviations: CLT, cadaveric liver transplantation; HCC, hepatocellular carcinoma; LDLT, living donor liver transplantation; PEI, percutaneous ethanol injection; RF, radiofrequency.

Stage 0 is very early disease, which is defined as a solitary liver cancer that measures $\leq 2 \mathrm{~cm}$ without tumor invasion into surrounding tissues.

Stage A is early disease, classified as patients who exhibit preserved liver function with a solitary $\mathrm{HCC}<5 \mathrm{~cm}$ in size, or up to 3 tumors each of which is $\leq 3 \mathrm{~cm}$ in size. Patients with stage 0 or stage A disease can be effectively treated with curative therapies, such as surgical resection, liver transplantation, or by percutaneous ablation methods, including percutaneous ethanol injection (PEI) and radiofrequency ablation (RFA). With these treatments it is possible to obtain complete responses with potential long-term cure, as reflected by a 5 -year survival better than $50 \%$ to $70 \%$.

The BCLC intermediate stage (stage B) consists of asymptomatic patients with well-preserved liver function, and multinodular or large tumor extension, without macrovascular invasion or extrahepatic spread (ES). Patients with stage B (intermediate) disease treated with transarterial embolization (TAE) or transarterial chemoembolization (TACE) have demonstrated a significant increase in survival compared with best supportive care (median survival, 20 months vs 16 months).

Patients with mild related symptoms and/or macrovascular invasion or ES are classified as advanced stage (BCLC stage C). Previously, no standard systemic therapy existed for the treatment of patients at this stage; however, two randomized controlled trials (RCTs) have now shown that sorafenib, an inhibitor of Raf kinase and vascular endothelial growth factor receptor (VEGFR), improves the overall survival of patients with stage $\mathrm{C}$ disease. Sorafenib is, therefore, now considered to be the standard treatment for advanced HCC. ${ }^{11,12}$ Patients with cancer symptoms, related to progressed liver failure, tumor growth with vascular involvement, ES, or physical impairment (performance status $>2$ ) are classified as stage D (end stage) disease; they do not benefit from antitumor treatments and should receive only the best available supportive care.

It should be noted that not all patients defined by each stage of BCLC are ultimately candidates for the suggested treatment modality.

For instance, TACE can be performed at an early stage in patients for whom RFA or PEI cannot be performed because of tumor location (proximity to a gallbladder, biliary tree, or blood vessel), or because of failed prior curative treatments or medical comorbidities. TACE is also the first-line therapy for downstaging tumors that exceed the criteria for transplantation or in patients awaiting orthotopic liver transplantation (OLT).

Moreover, even if guidelines for the management of HCC provide indications for the use of various treatments as monotherapies, in clinical practice a multimodal approach 
that combines various techniques is used, either as first-line therapy or as a rescue (second-line) approach after the failure of a monotherapy (Table 1$) \cdot{ }^{13,14}$

\section{Review of the natural history and diagnosis of hepatocellular carcinoma}

$\mathrm{HCC}$ is an insidious disease, with no particular or specific signs and symptoms of manifestation and whose behavior is usually unpredictable. Its natural history is also dependent on functional impairment of the underlying liver disease which often limits the application of therapeutic opportunities and influences survival. The spontaneous course of the unresectable disease has recently been evaluated in a meta-analysis which analyzed the survival rates of the placebo and untreated arms of several RCTs on HCC patients, showing that the 1 - and 2-year survival is extremely heterogeneous (Figure 2). ${ }^{15}$ Moreover, when studies were separated according to the BCLC stage, the 1-year survival was much higher in RCTs including only BCLC B or C patients (34\%) than in those also including BCLC D patients $(11 \%) .{ }^{15}$ For ethical reasons it is not possible to evaluate in RCTs the natural history of early HCC. However a milestone paper published in 1989 showed that 1- and 2-year overall survival of asymptomatic patients with $\mathrm{HCC}$ and cirrhosis was $96 \%$ and $50 \%$, respectively. ${ }^{16}$

Table I The proposed purpose of combination therapy

\begin{tabular}{ll}
\hline Contextual & Improved effectiveness over monotherapy for the \\
treatment of single lesions \\
- Improved effectiveness over monotherapy for the \\
treatment of multiple lesions \\
- Improved effectiveness over monotherapy for the \\
prevention of tumor recurrence \\
- Improved effectiveness over monotherapy for the \\
treatment of large or difficult lesions \\
- Rescue therapy after the failure of a first-line approach \\
- Improved effectiveness over monotherapy for the \\
prevention of tumor recurrence after complete \\
response (adjuvant treatment) \\
- To slow tumor progression for patients awaiting liver \\
transplantation (bridge to transplant) \\
- To reduce tumor size to meet orthotopic liver \\
transplantation criteria (downstaging) \\
- To allow for salvage transplantation in patients without \\
proven malignant disease after liver resection if \\
pathological findings (eg, evidence of vascular invasion) \\
indicate the patient is at high risk of tumor recurrence \\
("salvage" transplantation)
\end{tabular}

Note: Copyright (C) 2009, Native Publishing Group. Modified with permission from Cabibbo G, Latteri F, Antonucci M, Craxì A. Multimodal approaches to the treatment of hepatocellular carcinoma. Nat Clin Pract Gastroenterol Hepatol. 2009;6(3):159-169.
Despite the many treatment options, the prognosis of HCC remains dismal. A majority (70\% to $85 \%$ ) of patients present with advanced or unresectable disease. ${ }^{17}$ Since the stage of cancer dictates the therapeutic choice, early detection is a primary objective. The goal of cancer screening is to reduce mortality through a reduction in incidence of advanced disease.

Although the optimal methods of screening and the cost-effectiveness of surveillance (the repeated application of screening tests) for HCC remain to be established, systematic screening still offers the best hope for early diagnosis, treatment eligibility, and improved survival. ${ }^{10,18}$

"Recall policies" are the policies instituted to deal with an abnormal screening test result. Once a hepatic lesion is found during ultrasonographic surveillance, diagnosis of $\mathrm{HCC}$ is made through the application of some criteria that have been recently updated by Bruix and Sherman and have been endorsed by the American Association for the study of Liver Diseases. ${ }^{10}$ According to these criteria, patients with nodules $<1 \mathrm{~cm}$ in diameter detected by ultrasonography are followed up every 3 to 6 months in order to observe any variation of aspect or dimensions. Nodules $>1 \mathrm{~cm}$ in diameter should be investigated with at least one dynamic radiological study (4-phase multidetector $\mathrm{CT}$ scan or dynamic contrast enhanced MRI). When typical contrast-enhancing behavior of HCC is observed (ie, presence of a hypervascular pattern in arterial phase with a wash out of contrast during the venous and late phase) the lesion should be treated as HCC. If imaging findings are atypical for $\mathrm{HCC}$ or uncertain, a second contrast-enhanced study with the other imaging modality should be performed or the lesion should be biopsied (Figure 3). ${ }^{10}$

Several studies have evaluated the cost-effectiveness of the recall policies. ${ }^{19-21}$

\section{Overview of the pathophysiological processes associated with hepatocellular carcinoma}

Generally, HCC develops on a background of chronic liver disease or inflammation and cirrhosis in $70 \%$ to $90 \%$ of all cases. All risk factors for liver cirrhosis play a role in the hepatocellular carcinogenesis and liver cirrhosis per se is a precancerous condition. ${ }^{22}$

$\mathrm{HCC}$ is known to show a multistep progression from the hyperplastic nodule to early HCC and finally to moderately/ poorly differentiated HCC (Figure 4). Throughout the course of this pathway, nodules acquire evident changes in vascular supply with development of newborn unpaired arteries that 


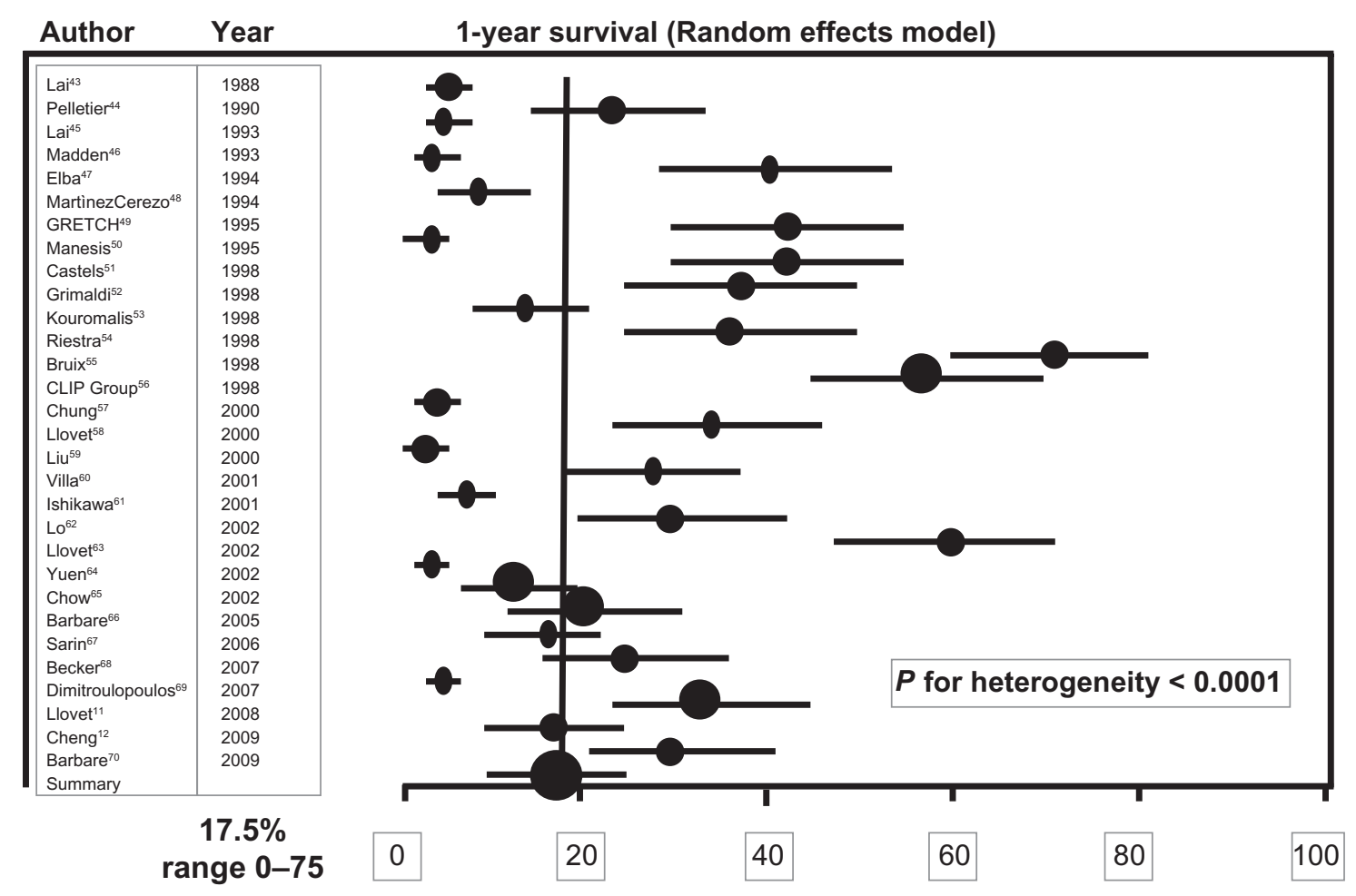

Figure 2 Forest plot of I-year survival rates of the placebo or untreated arms of 30 RCTs using random-effects model. Studies are arranged by publication year. Copyright $($ ) 2010, John Wiley and Sons. Adapted with permission from Cabibbo G, Enea M, Attanasio M, Bruix J, Craxì A, Cammà C. A meta-analysis of survival rates of untreated patients in randomized clinical trials of hepatocellular carcinoma. Hepatology. 20I0;5I(4):I274-1283.

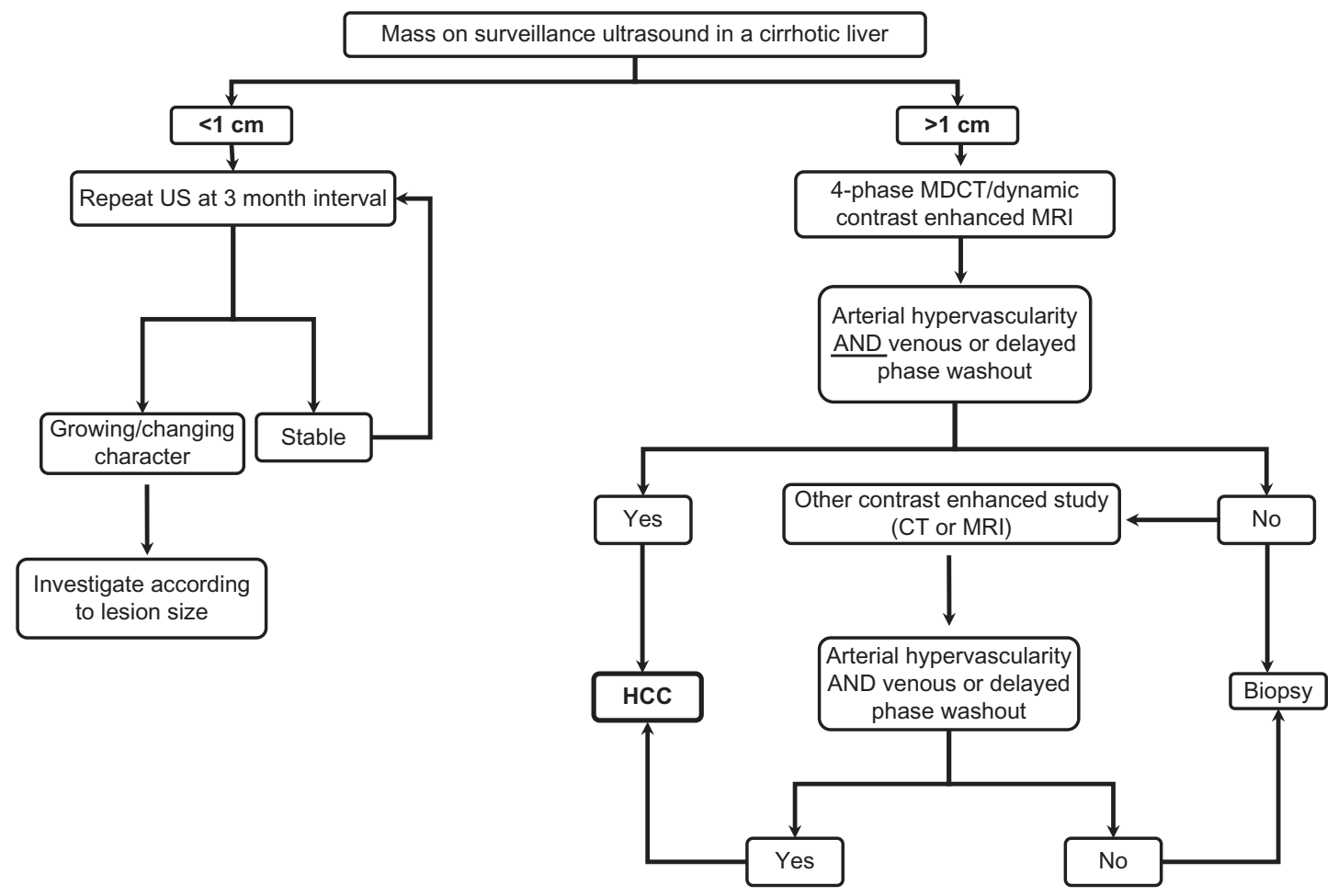

Figure 3 Algorithm for investigation of small nodules found on screening in patients at risk for hepatocellular carcinoma (HCC). Copyright $@ 2010$, American Association for the study of Liver Diseases. Adapted with permission from Bruix J, Sherman M. Management of hepatocellular carcinoma: an update. Hepatology. 20 I0; I-35. Available from: http://www.aasld.org/practiceguidelines/Documents/Bookmarked\%20practice\%20Guidelines/Hccupdate20I0.pdf. Accessed on Nov 3, 2010.

Abbreviations: MDCT, multidetector computed tomography scan; MRI, magnetic resonance imaging; US, ultrasound. 


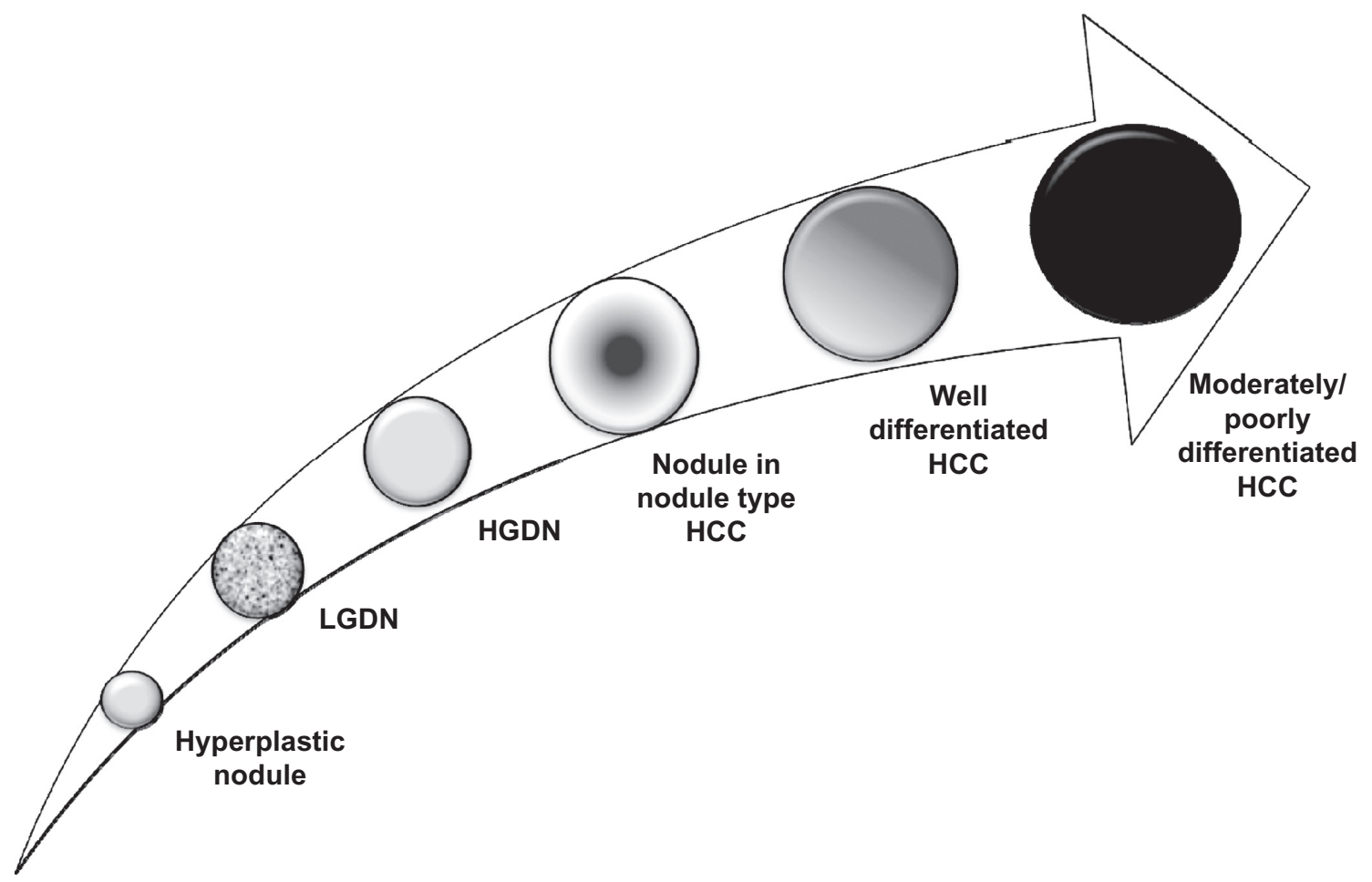

Figure 4 Schematic representation of multistep progression of human hepatocarcinogenesis. Differentiation between early-stage hepatocellular carcinoma (HCC) and premalignant lesion is extremely important.

Abbreviations: LGDN, low grade dysplastic nodule; HGDN, high grade dysplastic nodule.

progressively replace portal vessels, giving the nodule the typical hypervascular appearance.

The hepatocarcinogenetic process is mostly characterized by the appearance of dysplastic lesions (dysplastic phase) in the form of microscopic foci (large and small cell changes) and macroscopic dysplastic nodules (low and high grade). ${ }^{23,24}$ This phase is very important because patients harboring these lesions are at increased risk of developing HCC, allowing early tumor detection and consequently improving survival. The possibility of de novo development of HCC without premalignant antecedents is rare, but cannot be excluded.

High-grade dysplastic nodules are the most advanced precursors of HCC and small and well-differentiated HCCs with indistinct margins are the earliest and smallest recognizable forms of $\mathrm{HCC}$ (usually $<2 \mathrm{~cm}$ ).

Despite our growing comprehension of the different pathways altered in hepatocellular tumors, the molecular mechanisms that lead to malignant transformation of hepatocytes and give rise to a $\mathrm{HCC}$ are still poorly understood. Several epigenetic and genetic alterations are involved in hepatocellular tumorigenesis, leading to mutations in genes that control cell cycle, proliferation, and apoptosis. Different risk factors such as viral infections, oxidative stress, and cirrhotic inflammation induce the initiation of carcinogenesis and then the progressive occurrence of gene mutations contribute to the selection of cells that can proliferate and survive in an uncontrolled way. Principal mutations observed in HCC carcinogenesis are deletions or gains of chromosome segments, point mutations, and epigenetic changes such as hypermethylation of gene promoters. ${ }^{25}$

During the past few years several possible key molecular pathways involved in HCC's pathogenesis have been discovered and they represent important potential targets for experimental therapies. The mitogen-activated protein kinase (MAPK) pathway is a cascade of phosphorylation events mediated by four cellular kinases (Ras, Raf, MAP and extracellular signal related kinase [ERK]) that influence cellular proliferation, differentiation, and apoptosis and are frequently involved in HCC pathogenesis. The phosphoinositide-3 kinase/protein kinase B/mammalian target of rapamycin (PI3K/Akt/mTOR) pathway includes a group of cellular kinases that promote regulation of cell cycle and apoptosis, and it is frequently upregulated in certain subgroups of HCCs. Moreover, several growth factors and their receptors are, interestingly, involved in HCC pathogenesis. In particular both EGFR and VEGFR are overexpressed in 
tumor tissue and possibly play a role in neoplastic cell growth and metastatization. ${ }^{26}$

\section{Targeted treatment therapies - safety and efficacy}

As mentioned above, sorafenib is recommended as the firstline option in patients who cannot benefit from resection, transplantation, ablation, or transarterial chemoembolization, and still have preserved liver function. ${ }^{10}$

The multicenter SHARP trial randomly assigned 602 patients with inoperable HCC and Child-Pugh A cirrhosis to sorafenib (400 mg twice daily) or placebo. ${ }^{11}$ Overall survival, the primary end-point, was significantly longer in the sorafenib-treated patients (10.7 vs 7.9 months), as was time to radiologic progression (5.5 vs 2.8 months).

The magnitude of benefit was markedly less in the second trial ${ }^{12}$ than in the SHARP trial. In fact, the treated group in the Asian trial had a shorter survival duration than the control group in the SHARP trial (6.5 vs 7.9 months), despite the fact that both trials used the same entry criteria. Nevertheless, patients accrued to the Asian study were more ill at the start of therapy than those in the SHARP trial, with a generally worse performance status and more advanced stage of disease.

Sorafenib was generally well tolerated and the overall incidence of serious adverse events in the sorafenib and placebo groups was comparable (52\% and 54\%, respectively). Drug-related adverse events (diarrhea, hand-foot skin syndrome [HFSR], anorexia, weight loss, asthenia, alopecia, and voice changes), especially of grade 1 or 2 severity, were observed more frequently in the sorafenib group than in the placebo group ( $80 \%$ vs $52 \%$ ). The two most common grade 3 adverse reactions with sorafenib were HFSR $(8 \%)$ and diarrhea $(8 \%)$. There were no significant differences in discontinuation rates between the sorafenib and the placebo group (38\% and $37 \%$ respectively) because of adverse events. The safety profile of sorafenib was comparable to those of the subsequent Asia-Pacific Phase III trial that enrolled patients of Eastern countries with similar eligibility criteria.

However, reports of its tolerability and efficacy in a real-life setting (outside RCTs) are still scarce. A recent report, published as an abstract, showed that during treatment with sorafenib occurrence of adverse events of any grade is common ( $89 \%)$ and often requires dose reduction or discontinuation. Moreover, in this study, the overall 1-year survival rate was not significantly different between patients who received full dose and patients who received reduced dose. Dose-ranging studies in order to assess the individual effective dose may be required. ${ }^{27}$

Several new molecular targeted therapies are under clinical development for the treatment of advanced HCC including anti-EGFR molecules such as erlotinib, monoclonal antibodies against VEGF such as bevacizumab, and antiangiogenic agents such as sunitinib, brivanib, or linifanib (Table 2).

Bevacizumab is a recombinant humanized monoclonal antibody against VEGF-A. In a multicenter Phase II study, 46 patients with Child-Pugh A class cirrhosis and unresectable HCC with no extrahepatic disease and vascular involvement were enrolled; 6-month progression-free survival was achieved in $65 \%$ of these patients, with a $13 \%$ rate of partial response to treatment. ${ }^{28}$ Bevacizumab has also been evaluated in combination with chemotherapy in several Phase II studies. In a Phase II study, 33 patients, even with metastatic disease, treated with bevacizumab, gemcitabine, and oxaliplatin achieved a $20 \%$ response rate with an overall median survival time of 9.6 months. ${ }^{29}$ A Phase II trial of bevacizumab and erlotinib showed a response rate of $25 \%$ with a median overall survival of 68 weeks. ${ }^{30}$ On the basis of these results, bevacizumab, alone or in combination, may have an antitumoral activity against HCC, but its efficacy and tolerability profile, in particular because of the increased risk of variceal bleeding and thromboembolic events, requires further evaluation.

Brivanib alanate is an inhibitor of VEGFR and fibroblast growth factor receptor tyrosine kinases. At present a large randomized Phase III trial is studying brivanib as second-line therapy in HCC patients who have progressed on sorafenib. ${ }^{31}$

Sunitinib is another oral multikinase inhibitor against VEGFR1, VEGFR2, platelet derived growth factor receptor (PDGFR) alfa and beta, c-Kit, FLT3, and RET kinases. After two Phase II trials ${ }^{32,33}$ which analyzed efficacy and tolerability of sunitinib in advanced HCC, a Phase III trial comparing sunitinib and sorafenib was conducted. Unfortunately it has been recently discontinued because of the high incidence of serious adverse effects in the sunitinib arm of study. ${ }^{31}$

Erlotinib is an oral EGFR inhibitor against its tyrosine kinase domain. Two Phase II studies investigated efficacy of erlotinib in advanced $\mathrm{HCC}^{34,35}$ and a Phase III trial in combination with sorafenib is ongoing. ${ }^{31}$ A combination of erlotinib and bevacizumab versus sorafenib is now being studied in a multicenter Phase II trial. ${ }^{31}$

Linifanib (ABT-869) is an oral agent that acts as a selective inhibitor of VEGF and PDGF tyrosine kinase receptors that 
Table 2 Systemic therapy trials in advanced hepatocellular carcinoma (HCC)

\begin{tabular}{|c|c|c|c|c|c|}
\hline Regimen/trial name & $\begin{array}{l}\text { Study } \\
\text { author }\end{array}$ & Phase & No. of patients & $\begin{array}{l}\text { Results/preliminary } \\
\text { data* }\end{array}$ & $\begin{array}{l}\text { Drug name/mechanism } \\
\text { of action }\end{array}$ \\
\hline $\begin{array}{l}\text { Phase II trial evaluating } \\
\text { clinical and biological } \\
\text { effects of bevacizumab } \\
\text { in unresectable } \\
\text { hepatocellular carcinoma }\end{array}$ & Siegel et $\mathrm{a}^{28}$ & II & 46 & $\begin{array}{l}\text { OS } 12.4 \text { months, } \\
\text { PSF } 6.9 \text { months }\end{array}$ & Bevacizumab: mAb against VEGF \\
\hline $\begin{array}{l}\text { Phase II study of } \\
\text { gemcitabine, oxaliplatin } \\
\text { in combination with } \\
\text { bevacizumab in } \\
\text { patients with advanced } \\
\text { hepatocellular carcinoma }\end{array}$ & Zhu et $\mathrm{a}^{29}$ & II & 17 & $\begin{array}{l}\text { OS } 9.6 \text { months, PFS } \\
5.3 \text { months }\end{array}$ & $\begin{array}{l}\text { Bevacizumab: mAb against VEGF; } \\
\text { oxaliplatin: alkylating agent, inhibition of } \\
\text { DNA synthesis; gemcitabine: nucleoside } \\
\text { analog, arrest of DNA replication }\end{array}$ \\
\hline $\begin{array}{l}\text { Phase II trial of the } \\
\text { combination of } \\
\text { bevacizumab and } \\
\text { erlotinib in patients } \\
\text { who have advanced } \\
\text { hepatocellular carcinoma }\end{array}$ & Thomas et $\mathrm{al}^{30}$ & $\|$ & 40 & $\begin{array}{l}\text { OS } 68 \text { weeks, PFS } \\
39 \text { weeks }\end{array}$ & $\begin{array}{l}\text { Bevacizumab: } m A b \text { against VEGF; } \\
\text { erlotinib: RTK inhibits EGFRI }\end{array}$ \\
\hline $\begin{array}{l}\text { Comparison of brivanib } \\
\text { and best supportive care } \\
\text { to placebo for treatment } \\
\text { of liver cancer for those } \\
\text { subjects who have failed } \\
\text { sorafenib treatment }\end{array}$ & & III & 340 & Recruiting participants ${ }^{31}$ & $\begin{array}{l}\text { Brivanib: inhibition of FGFI and } \\
\text { VEGFR2 }\end{array}$ \\
\hline $\begin{array}{l}\text { Study of sunitinib malate } \\
\text { versus sorafenib in } \\
\text { patients with inoperable } \\
\text { liver cancer }\end{array}$ & & III & 1200 & $\begin{array}{l}\text { Discontinued on April } \\
2010 \text { because of high } \\
\text { rate of severe adverse } \\
\text { effect on sunitinib arm }{ }^{31}\end{array}$ & $\begin{array}{l}\text { Sunitinib: inhibition of VEGF-R2 and } \\
\text { PDGF-R beta tyrosine kinase }\end{array}$ \\
\hline $\begin{array}{l}\text { Nexavar-Tarceva } \\
\text { Combination Therapy } \\
\text { for First Line Treatment } \\
\text { of Patients Diagnosed } \\
\text { With Hepatocellular } \\
\text { Carcinoma (SEARCH) }\end{array}$ & & III & & Recruiting participants ${ }^{31}$ & $\begin{array}{l}\text { Erlotinib: RTK inhibits EGFRI; } \\
\text { sorafenib: multikinase inhibitor of Raf, } \\
\text { VEGFR2, PDGFR, FLT3, MEK and ERK }\end{array}$ \\
\hline $\begin{array}{l}\text { Bevacizumab and } \\
\text { erlotinib or sorafenib } \\
\text { as first-line therapy in } \\
\text { treating patients with } \\
\text { advanced liver cancer }\end{array}$ & Thomas et al ${ }^{30}$ & ॥ & 120 & Recruiting participants ${ }^{31}$ & $\begin{array}{l}\text { Bevacizumab: mAb against VEGF; } \\
\text { erlotinib: RTK inhibits EGFR I; } \\
\text { sorafenib: multikinase inhibitor of Raf, } \\
\text { VEGFR2, PDGFR, FLT3, MEK and ERK }\end{array}$ \\
\hline $\begin{array}{l}\text { Phase II study of } \\
\text { ABT- } 869 \text { in hepatocellular } \\
\text { carcinoma (HCC) }\end{array}$ & Toh et $\mathrm{a}^{36}$ & ॥ & 44 & Active, not recruiting ${ }^{31}$ & $\begin{array}{l}\text { ABT-869: selective inhibitor of VEGF } \\
\text { and PDGF tyrosine kinase receptors }\end{array}$ \\
\hline $\begin{array}{l}\text { Efficacy and tolerability } \\
\text { of ABT- } 869 \text { versus } \\
\text { sorafenib in advanced } \\
\text { hepatocellular carcinoma }\end{array}$ & & III & & Recruiting participants ${ }^{31}$ & $\begin{array}{l}\text { ABT-869: selective inhibitor of VEGF } \\
\text { and PDGF tyrosine kinase receptors; } \\
\text { sorafenib: multikinase inhibitor of Raf, } \\
\text { VEGFR2, PDGFR, FLT3, MEK and ERK }\end{array}$ \\
\hline
\end{tabular}

was recently evaluated in a Phase II trial conducted on Child-Pugh A or B cirrhotic patients that reported a median time to progression and progression-free survival of 112 days with a median overall survival of 295 days. ${ }^{36}$ Preliminary pharmacokinetics analysis in Child Pugh A and B patients showed that degree of hepatic impairment of tumor extent do not influence linifanib pharmacokinetics. ${ }^{37}$ Its safety profile was acceptable and therefore a new Phase III study 
comparing linifanib with sorafenib in patients with advanced $\mathrm{HCC}$ is ongoing. ${ }^{31}$

\section{Implications for future work and enhanced patient care}

Despite the use of aggressive treatments such as resection, OLT, PEI, RFA, and TACE, tumor recurrence and the development of extrahepatic metastases continue to have a marked effect on survival of patients with HCC.

Several steps are required to improve the effectiveness of HCC therapy, including the implementation of screening programs to increase the number of patients diagnosed in early stages of disease, and improving patients' access to specialized, multidisciplinary treatments (ie, pharmacological, interventional, radiological, and surgical).

Image-guided loco-regional therapies have long been used in the setting of combined treatment strategies to improve their efficacy and effectiveness.

An accepted indication is the use of interventional treatment in patients awaiting transplantation to prevent tumor progression when the waiting time exceeds 6 months. ${ }^{38}$
A combination of TACE followed by RFA or PEI has been used to minimize heat loss due to perfusion-mediated tissue cooling and thus increase the therapeutic effect of RFA. ${ }^{13,14}$

Combination treatment with RFA plus PEI can improve survival compared with the use of RFA alone in selected patients. ${ }^{39}$ However, large RCTs should be performed to confirm the efficacy of these combination therapies.

The impact of sorafenib on advanced-stage HCC is a landmark finding in the treatment of liver cancer. Moreover, the potential value of antiangiogenic and antiproliferative properties of sorafenib is currently under evaluation for early and intermediate stages in preventing recurrence. In fact, two studies ${ }^{31}$ that aim to evaluate the effect of sorafenib versus placebo after curative treatment (adjuvant therapy), and the effect of sorafenib versus placebo in combination with TACE (combined therapy), have already been initiated.

The Sorafenib as Adjuvant Treatment in the Prevention Of Recurrence of Hepatocellular Carcinoma (STORM) RCT is an international study that is evaluating effects of sorafenib versus placebo after resection or local ablation. The primary end-point of this RCT is recurrence-free survival. The Sorafenib or Placebo in Combination with TACE in hepatocellular carcinoma (SPACE) is investigating the
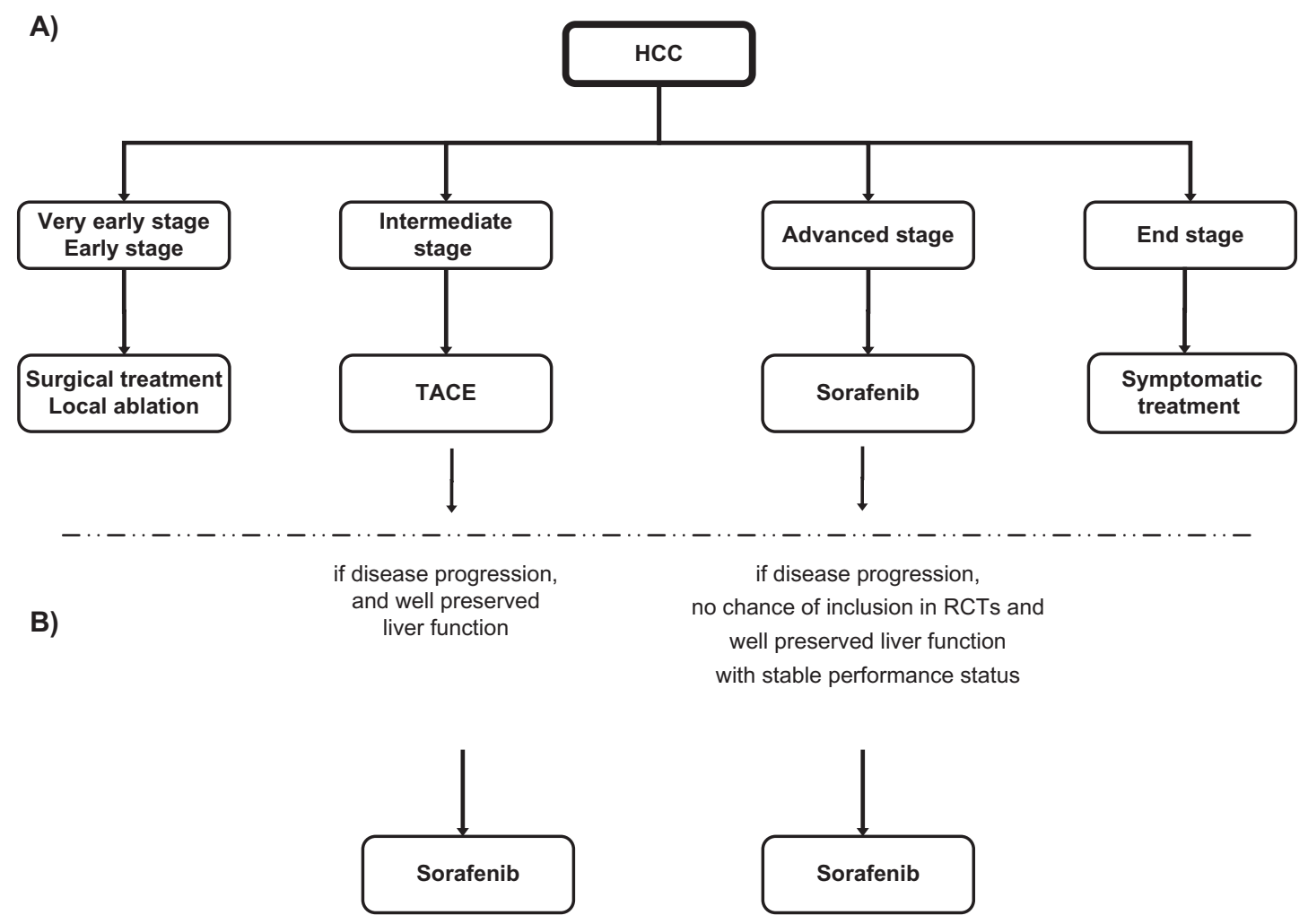

Figure 5 A) Treatment allocation according to American Association of Liver Diseases guidelines; ${ }^{10}$ B) Proposed extended use of sorafenib outside RCTs for intermediate and advanced stage after disease progression (growth lesions and new lesions)..$^{40-42}$

Abbreviation: TACE, transarterial chemoembolization. 
combination of sorafenib and TACE in patients with intermediate $\mathrm{HCC}$ with the aim of reducing risk of local relapse after this procedure.

Recently, although in the absence of solid evidence, panels of experts proposed shifting therapy to sorafenib in patients in intermediate stage if they showed poor tolerance or disease progression (new lesions or growth lesions) after first or second TACE, ${ }^{40,41}$ and suggested continuing treatment with sorafenib even if patients previously treated with sorafenib showed disease progression during treatment ${ }^{42}$ (Figure 5). However, well-conducted large studies are needed to evaluate these treatment approaches.

Several targeted agents are under investigation, which show encouraging results in Phase II studies. Their efficacy and safety has yet to be proven in Phase III RCTs. The combination of multiple, targeted agents may be the next logical step in the treatment of HCC due to the strong rationale of inhibiting signaling pathways in hepatocarcinogenesis.

\section{Conclusions and discussion}

Undoubtedly, the best way to prevent the development of HCC is the prevention of risk factors leading to chronic injury (primary prevention). Vaccination against hepatitis $\mathrm{B}(\mathrm{HBV})$ has decreased the incidence of HBV-related HCC. Vaccination against hepatitis $\mathrm{C}(\mathrm{HCV})$ is not yet possible, and prevention of $\mathrm{HCV}$ infection relies on the implementation of adequate public health measures.

A major challenge remains the early diagnosis of HCC in order to allow a potentially curative treatment approach (secondary prevention). HCC surveillance by abdominal ultrasound should be performed on all patients at risk at 6-month intervals.

Diagnosis of HCC at an early stage provides the opportunity for therapy (resection, OLT, percutaneous ablation) with the aim of complete response and potential long-term cure.

TACE is the recommended treatment modality for $\mathrm{HCC}$ at intermediate stage with well-preserved liver function.

Sorafenib is the standard treatment for intermediate or advanced stage HCC beyond the benefit of liver transplantation, surgery, and loco-regional therapies. It is suggested as the control in first-line trials for advanced HCC. Trials comparing new agents with sorafenib and new agents in combination with sorafenib against sorafenib alone are a priority. In the absence of standard-of-care second-line therapy, randomized second-line trials should be placebo controlled.

Despite the availability of several treatment options, tumor recurrence and metastatic disease continue to have an important role on survival, and for this reason there is urgent need for effective neoadjuvant and adjuvant therapies in order to enhance benefits of these approaches. The advent of systemic therapies for HCC and in particular the success of antiangiogenic molecules such as sorafenib has opened a new window on promising clinical research that may potentially affect the future treatment of this disease. Sorafenib has been shown to effectively prolong survival in patients with advanced HCC and preserved liver function but many other molecularly targeted agents, used alone or in combination, are in different stages of clinical development. Combination of systemic therapies with local treatments in patients with $\mathrm{HCC}$ is still being evaluated but holds the promise of further improvements in patient outcomes. Well-conducted, randomized controlled trials to examine the effectiveness of different multimodal approaches are urgently needed.

Given the complexity of the disease (in particular for the presence of chronic liver disease) and the large number of potentially useful therapies, it is not surprising that the expertise of many physicians is required to provide optimal care to patients with HCC. Patients diagnosed with liver cancer should be referred to multidisciplinary teams including hepatologists, gastroenterologists, surgical oncologists, transplant surgeons, medical oncologists, radiation oncologists, diagnostic radiologists, interventional radiologists, primary care physicians, palliative care physicians, and allied health professionals, all of whom should play an active role in the care of these patients. Treatment decisions should be discussed in multidisciplinary meetings, as no single treatment strategy can be applied to all patients, and treatment must be individualized.

\section{Disclosure}

The authors disclose no conflicts of interest.

\section{References}

1. Parkin DM, Bray F, Ferlay J, Pisani P. Global cancer statistics 2002. CA Cancer J Clin. 2005;55:74-108.

2. Sangiovanni A, Del Ninno E, Fasani P, et al. Increased survival of cirrhotic patients with a hepatocellular carcinoma detected during surveillance. Gastroenterology. 2004;126:1005-1014.

3. Bruix J, Sherman M; Practice Guidelines Committee, American Association for the Study of Liver Diseases. Management of hepatocellular carcinoma. Hepatology. 2005;42:1208-1236.

4. Bugianesi E, Leone N, Vanni E, et al. Expanding the natural history of nonalcoholic steatohepatitis: from cryptogenic cirrhosis to hepatocellular carcinoma. Gastroenterology. 2002;123(1):134-140.

5. Bugianesi E. Non-alcoholic steatohepatitis and cancer. Clin Liver Dis. 2007;11(1):191-207.

6. Cammà C, Di Marco V, Cabibbo G, Latteri F, Sandonato L, Parisi P, et al. Survival of patients with hepatocellular carcinoma in cirrhosis: a comparison of BCLC, CLIP and GRETCH staging systems. Aliment Pharmacol Ther. 2008;28:62-75.

7. Cammà $\mathrm{C}$, Cabibbo G. Prognostic scores for hepatocellular carcinoma: none is the winner. Liver Int. 2009;29(4):478-840. 
8. Tandon P, Garcia-Tsao G. Prognostic indicators in hepatocellular carcinoma: a systematic review of 72 studies. Liver Int. 2009;29: $502-510$.

9. Llovet JM, Brú C, Bruix J. Prognosis of hepatocellular carcinoma: the BCLC staging classification. Semin Liver Dis. 1999;19(3):329-338.

10. Bruix J, Sherman M. Management of hepatocellular carcinoma: an update. Hepatology. 2010;1-35. Available from: http://www.aasld. org/practiceguidelines/Documents/Bookmarked\%20practice $\% 20$ Guidelines/Hccupdate2010.pdf. Accessed on Nov 3, 2010.

11. Llovet JM, Ricci S, Mazzaferro V, et al. SHARP Investigators Study Group. Sorafenib in advanced hepatocellular carcinoma. NEngl J Med. 2008;359(4):378-390.

12. Cheng AL, Kang YK, Chen Z, et al. Efficacy and safety of sorafenib in patients in the Asia-Pacific region with advanced hepatocellular carcinoma: a phase III randomised, double-blind, placebo-controlled trial. Lancet Oncol. 2009;10(1):25-34.

13. Cabibbo G, Latteri F, Antonucci M, Craxì A. Multimodal approaches to the treatment of hepatocellular carcinoma. Nat Clin Pract Gastroenterol Hepatol. 2009;6(3):159-169.

14. Wang W, Shi J, Xie WF. Transarterial chemoembolization in combination with percutaneous ablation therapy in unresectable hepatocellular carcinoma: a meta-analysis. Liver Int. 2010;30(5):741-749.

15. Cabibbo G, Enea M, Attanasio M, Bruix J, Craxì A, Cammà C. A metaanalysis of survival rates of untreated patients in randomized clinical trials of hepatocellular carcinoma. Hepatology. 2010;51(4):1274-1283.

16. Cottone M, Virdone R, Fusco G, et al. Asymptomatic hepatocellular carcinoma in Child's A cirrhosis. A comparison of natural history and surgical treatment. Gastroenterology. 1989;96(6):1566-1571.

17. Thomas MB, Zhu AX. Hepatocellular carcinoma: the need for progress. J Clin Oncol. 2005;23(13):2892-2899.

18. Cabibbo G, Craxì A. Hepatocellular cancer: optimal strategies for screening and surveillance. Dig Dis. 2009;27(2):142-147.

19. Sangiovanni A, Manini MA, Iavarone M, et al. The diagnostic and economic impact of contrast imaging techniques in the diagnosis of small hepatocellular carcinoma in cirrhosis. Gut. 2010;59(5):638-644.

20. Leoni S, Piscaglia F, Golfieri R, et al. The impact of vascular and nonvascular findings on the noninvasive diagnosis of small hepatocellular carcinoma based on the EASL and AASLD criteria. Am J Gastroenterol. 2010;105(3):599-609.

21. Piscaglia F, Leoni S, Cabibbo G, et al. Cost analysis of recall strategies for non-invasive diagnosis of small hepatocellular carcinoma. Dig Liver Dis. 2010;42(10):729-734.

22. Parkin DM, Bray FI, Devesa SS. Cancer burden in the year 2000. The global picture. Eur J Cancer. 2001;37(Suppl 8):S4-S66.

23. International Working Party. Terminology of nodular hepatocellular lesions. Hepatology. 1995;22:983-993.

24. International Consensus Group for Hepatocellular Neoplasia. The International Consensus Group for Hepatocellular Neoplasia. Pathologic diagnosis of early hepatocellular carcinoma: a report of the international consensus group for hepatocellular neoplasia. Hepatology. 2009;49:658-664.

25. Zucman-Rossi J. Molecular classification of hepatocellular carcinoma. Dig Liver Dis. 2010;42 Suppl 3:S235-S241.

26. Thomas MB, Jaffe D, Choti MM, et al. Hepatocellular Carcinoma: Consensus Recommendations of the National Cancer Institute Clinical Trials Planning Meeting. J Clin Oncol. [Epub 2010 Aug].

27. Cabibbo G, Di Marco V, Cammà C, et al. Sorafenib for hepatocellular carcinoma: a practice experience. ILCA 2010 book of abstracts. p 162.

28. Siegel AB, Cohen EI, Ocean A, et al. Phase II trial evaluating the clinical and biologic effects of bevacizumab in unresectable hepatocellular carcinoma. J Clin Oncol. 2008;26(18):2992-2998.

29. Zhu AX, Blaszkowsky LS, Ryan DP, et al. Phase II study of gemcitabine and oxaliplatin in combination with bevacizumab in patients with advanced hepatocellular carcinoma. J Clin Oncol. 2006;24(12): 1898-1903.

30. Thomas MB, Morris JS, Chadha R, et al. Phase II trial of the combination of bevacizumab and erlotinib in patients who have advanced hepatocellular carcinoma. J Clin Oncol. 2009;27(6):843-850.
31. www.clinicaltrials.gov.

32. Faivre S, Raymond E, Boucher E, et al. Safety and efficacy of sunitinib in patients with advanced hepatocellular carcinoma: an open-label, multicentre, phase II study. Lancet Oncol. 2009;10(8):794-800.

33. Zhu AX, Sahani DV, Duda DG, et al. Efficacy, safety, and potential biomarkers of sunitinib monotherapy in advanced hepatocellular carcinoma: a phase II study. J Clin Oncol. 2009;27(18):3027-3035.

34. Philip PA, Mahoney MR, Allmer C, et al. Phase II study of Erlotinib (OSI-774) in patients with advanced hepatocellular cancer. J Clin Oncol. 2005;23(27):6657-6663.

35. Thomas MB, Chadha R, Glover K, et al. Phase 2 study of erlotinib in patients with unresectable hepatocellular carcinoma. Cancer. 2007;110(5):1059-1067.

36. Toh H, Chen P, Carr BI, et al. A phase II study of ABT-869 in hepatocellular carcinoma (HCC): interim analysis. J Clin Oncol. 2009;27: 222s:abstr 4581.

37. Gupta N, Chiu Y, Toh HC, et al. Preliminary pharmacokinetics and safety comparison of Child Pugh A vs. Child Pugh B patients enrolled in a phase 2 study of Linifanib (ABT-869) in Hepatocellular Carcinoma [abstract]. ESMO. 2010;237.

38. Belghiti J, Carr BI, Greig PD, Lencioni R, Poon RT. Treatment before liver transplantation for HCC. Ann Surg Oncol. 2008;15:993-1000.

39. Zhang YJ, Liang HH, Chen MS, et al. Hepatocellular carcinoma treated with radiofrequency ablation with or without ethanol injection: a prospective randomized trial. Radiology. 2007;244(2):599-607.

40. Raoul JL, Sangro B, Forner A, et al. Evolving strategies for the management of intermediate-stage hepatocellular carcinoma: Available evidence and expert opinion on the use of transarterial chemoembolization. Cancer Treat Rev. [2010; Aug 17 [Epub ahead of print].

41. Piscaglia F, Bolondi L. The intermediate hepatocellular carcinoma stage: Should treatment be expanded? Dig Liver Dis. 2010;42 Suppl 3: S258-S263.

42. Peck-Radosavljevic M, Greten TF, Lammer J, et al. Consensus on the current use of sorafenib for the treatment of hepatocellular carcinoma. Eur J Gastroenterol Hepatol. 2010;22(4):391-398.

43. Lai CL, Wu PC, Chan GC, Lok AS, Lin HJ. Doxorubicin versus no antitumor therapy in inoperable hepatocellular carcinoma. A prospective randomized trial. Cancer. 1988;62:479-483.

44. Pelletier G, Roche A, Ink O, Anciaux ML, Derhy S, Rougier P, et al. A randomized trial of hepatic arterial chemoembolization in patients with unresectable hepatocellular carcinoma. J Hepatol. 1990;11:181-184.

45. Lai CL, Lau JY, Wu PC, et al. Recombinant interferon-alpha in inoperable hepatocellular carcinoma: a randomized controlled trial. Hepatology 1993;17:389-394.

46. Madden MV, Krige JE, Bailey S, et al. Randomised trial of targeted chemotherapy with lipiodol and 5-epidoxorubicin compared with symptomatic treatment for hepatoma. Gut. 1993;34:1598-1600.

47. Elba S, Giannuzzi V, Misciagna G, Manghisi OG. Randomized controlled trial of tamoxifen versus placebo in inoperable hepatocellular carcinoma. Ital J Gastroenterol. 1994;26:66-68.

48. Martínez Cerezo FJ, Tomás A, Donoso L, et al. Controlled trial of tamoxifen in patients with advanced hepatocellular carcinoma. $J$ Hepatol. 1994;20:702-706

49. Groupe d'Etude et de Traitement du Carcinome Hépatocellulaire. A comparison of lipiodol chemoembolization and conservative treatment for unresectable hepatocellular carcinoma. $N$ Engl $J$ Med. 1995;332:1256-1261.

50. Manesis EK, Giannoulis G, Zoumboulis P, Vafiadou I, Hadziyannis SJ. Treatment of hepatocellular carcinoma with combined suppression and inhibition of sex hormones: a randomized, controlled trial. Hepatology. 1995;21:1535-1542.

51. Castells A, Bruix J, Brú C, et al. Treatment of hepatocellular carcinoma with tamoxifen: a double-blind placebo-controlled trial in 120 patients. Gastroenterology. 1995;109:917-922.

52. Grimaldi C, Bleiberg H, Gay F, et al. Evaluation of antiandrogen therapy in unresectable hepatocellular carcinoma: results of a European Organization for Research and Treatment of Cancer multicentric double-blind trial. J Clin Oncol. 1998;16:411-417. 
53. Kouroumalis E, Skordilis P, Thermos K, Vasilaki A, Moschandrea J, Manousos ON. Treatment of hepatocellular carcinoma with octreotide: a randomised controlled study. Gut. 1998;42:442-447.

54. Riestra S, Rodriguez M, Delgado M, et al. Tamoxifen does not improve survival of patients with advanced hepatocellular carcinoma. J Clin Gastroenterol. 1998;26:200-203.

55. Bruix J, Llovet JM, Castells A, et al. Transarterial embolization versus symptomatic treatment in patients with advanced hepatocellular carcinoma: results of a randomized, controlled trial in a single institution. Hepatology. 1998;27:1578-1583.

56. Tamoxifen in treatment of hepatocellular carcinoma: a randomised controlled trial. CLIP Group (Cancer of the Liver Italian Programme). Lancet. 1998;352:17-20.

57. Chung YH, Song IH, Song BC, et al. Combined therapy consisting of intraarterial cisplatin infusion and systemic interferon-alpha for hepatocellular carcinoma patients with major portal vein thrombosis or distant metastasis. Cancer. 2000;88:1986-1991.

58. Llovet JM, Sala M, Castells L, et al. Randomized controlled trial of interferon treatment for advanced hepatocellular carcinoma. Hepatology. 2000;31:54-58.

59. Liu CL, Fan ST, Ng IO, Lo CM, Poon RT, Wong J. Treatment of advanced hepatocellular carcinoma with tamoxifen and the correlation with expression of hormone receptors: a prospective randomized study. Am J Gastroenterol. 2000;95:218-222.

60. Villa E, Ferretti I, Grottola A, et al. Hormonal therapy with megestrol in inoperable hepatocellular carcinoma characterized by variant oestrogen receptors. Br J Cancer. 2001;84:881-885.

61. Ishikawa $\mathrm{T}$, Ichida $\mathrm{T}$, Sugitani $\mathrm{S}$, et al. Improved survival with oral administration of enteric-coated tegafur/uracil for advanced stage IV-A hepatocellular carcinoma. J Gastroenterol Hepatol. 2001;16:452-459.
62. Lo CM, Ngan H, Tso WK, et al. Randomized controlled trial of transarterial lipiodol chemoembolization for unresectable hepatocellular carcinoma. Hepatology. 2002;35:1164-1171.

63. Llovet JM, Real MI, Montaña X, et al. Arterial embolisation or chemoembolisation versus symptomatic treatment in patients with unresectable hepatocellular carcinoma: a randomised controlled trial. Lancet. 2002;359:1734-1739.

64. Yuen MF, Poon RT, Lai CL, et al. A randomized placebo-controlled study of long-acting octreotide for the treatment of advanced hepatocellular carcinoma. Hepatology. 2002;36:687-691.

65. Chow PK, Tai BC, Tan CK, et al. High-dose tamoxifen in the treatment of inoperable hepatocellular carcinoma: A multicenter randomized controlled trial. Hepatology. 2002;36:1221-1226.

66. Barbare JC, Bouché O, Bonnetain F, et al. Randomized controlled trial of tamoxifen in advanced hepatocellular carcinoma. J Clin Oncol. 2005;23:4338-4346.

67. Sarin SK, Kumar M, Garg S, Hissar S, Pandey C, Sharma BC. High dose vitamin $\mathrm{K} 3$ infusion in advanced hepatocellular carcinoma. J Gastroenterol Hepatol. 2006;21:1478-1482.

68. Becker G, Allgaier HP, Olschewski M, Zähringer A, Blum HE; HECTOR Study Group. Long-acting octreotide versus placebo for treatment of advanced HCC: a randomized controlled double-blind study. Hepatology. 2007;45:9-15.

69. Dimitroulopoulos D, Xinopoulos D, Tsamakidis K, et al. Long acting octreotide in the treatment of advanced hepatocellular cancer and overexpression of somatostatin receptors: randomized placebo-controlled trial. World J Gastroenterol. 2007;13:3164-3170.

70. Barbare JC, Bouché O, Bonnetain F, et al. Treatment of advanced hepatocellular carcinoma with long-acting octreotide: A phase III multicenter, randomised, double blind placebo-controlled study. Eur J Cancer. 2009;45:1788-1797.
Hepatic Medicine: Evidence and Research

\section{Publish your work in this journal}

Hepatic Medicine: Evidence and Research is an international, peerreviewed, open access journal covering all aspects of adult and pediatric hepatology in the clinic and laboratory including the following topics: Pathology, pathophysiology of hepatic disease; Investigation and treatment of hepatic disease; Pharmacology of drugs used for

\section{Dovepress}

the treatment of hepatic disease. Issues of patient safety and quality of care will also be considered. The manuscript management system is completely online and includes a very quick and fair peer-review system, which is all easy to use. Visit http://www.dovepress.com/ testimonials.php to read real quotes from published authors.

Submit your manuscript here: http://www.dovepress.com/hepatic-medicine-evidence-and-research-journal 